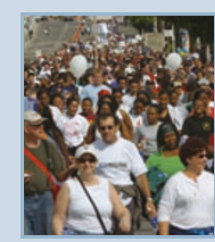

\author{
p696 Snail's pace: \\ UK's ambitious \\ biobank project is \\ trailing its counterpart \\ in Japan.
}

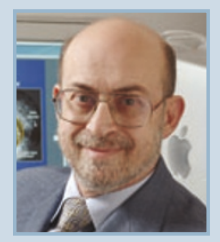

p700 Heart to heart: Cardiologist Steve Nissen explains why he refuses to take consulting fees.

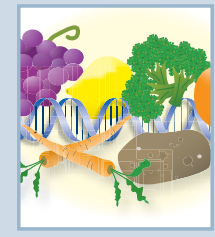

p701 Food for thought: Can a diet designed for your DNA cut disease risk?

\title{
Skepticism greets India's new AIDS statistics
}

The Indian health ministry in late May announced that new HIV infections in the country had increased by 28,000 over the previous year. The numbers have stoked a lingering controversy over the magnitude of the country's AIDS epidemic.

India's National AIDS Control Organization (NACO) based its numbers on data collected from 659 sentinel sites, including clinics for sexually transmitted diseases, drug rehabilitation centers, prenatal care clinics and groups of female sex workers. The organization says India has an estimated 5.134 million cases, ranking second only to South Africa's 5.3 million.

At $0.91 \%$, the prevalence remains below $1 \%$, considered the tipping point for AIDS. But in some parts of India, more than 4 in every 100 people is infected. The number of high-prevalence districts also rose from 49 to 111 in 2004.

Still, the increase in infections in 2004 is a 95\% drop compared with 2003, when NACO recorded 520,000 new cases. NACO director
S.Y. Quraishi attributes this dramatic drop to the government's strategy to target prevention efforts on high-risk groups in states where the infection rate is greater than $1 \%$. "We are tackling the problem at the root cause and are on the right track," Quraishi says.

But international experts quickly disputed the numbers, saying there are no studies that show significant behavior change or awareness levels to substantiate the government's claims.

The low numbers could lead to complacency

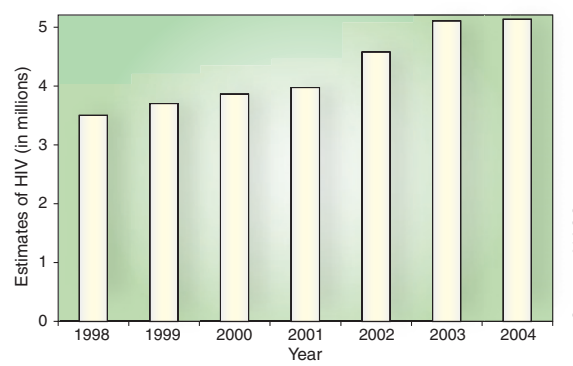

HIV/AIDS infections in India are rising steadily. and slow down HIV prevention efforts, the experts warn. "This is the time to have an all-out assault on the epidemic to win the battle," says Jon Lidén, head of communications for the Global Fund to Fight AIDS, Tuberculosis and Malaria.

If prevention efforts stall, infections could resurge, even in areas - such as the southern state of Tamil Nadu — where incidence has plateaued for the past four years. "HIV is still increasing in India and remains a formidable challenge," says Denis Broun, UNAIDS country coordinator in India.

A week after the government's announcement, the health ministry, UNAIDS and the World Health Organization clarified that the number 28,000 does not include deaths due to AIDS.

The report reveals other trends: infections in rural India continued to rise to $59 \%$ of all HIV infections. Overall prevalence in the southern state of Andhra Pradesh surpassed 2\%, and is continuing to rise in both high-risk groups and the general population in several other states.

T.V.Padma, New Delhi

\section{International partnership launches malaria model in Zambia}

A new partnership between the African nation

of Zambia and several international aid

agencies aims to cut malaria deaths by $75 \%$

in the next three years. The scheme is one of several new efforts to step up malaria control.

"The next three to five years are extremely important for malaria," says Kent Campbell, director of the partnership at PATH, a nonprofit aid organization in Seattle.

The Malaria Control and Evaluation Partnership in Africa aims to reduce malaria deaths by rapidly improving access to insecticide-treated bed nets and medicines and to indoor mosquito-control methods such as house spraying. The Zambian government has pledged to provide $90 \%$ of households with insecticide-treated nets and rapidly treat $60 \%$ of patients with antimalarial drugs by 2008 .

"We will control malaria in Zambia and show the world that not only can malaria be controlled, but that it must be controlled now," Brian Chituwo, Zambia's health minister, said at the World Health Assembly in May. Malaria is the number-one killer of African children under five.
The program is funded through PATH by a nine-year \$35 million grant from the Bill \& Melinda Gates Foundation. Local staff will monitor aspects of the program in real time and gauge how each cuts deaths and boosts economic growth in the area. For example, if access to bed nets increases but child mortality does not fall, the program's staff will know in months rather than years, says Campbell.

The ultimate goal is for the Zambian program to set an example for other diseaseplagued nations. "We want develop a model that will begin to encourage other countries to make similar commitments," says Campbell.

Despite previous control efforts, the burden of malaria may be increasing. The World Health Organization estimates that there are up to 500 million cases of malaria each year, most of them in Africa. The organization is planning a new program to reduce shortages of artemisinin-based combination drugsthe most effective and expensive malaria treatments on the market-by encouraging more African farmers to grow the plant.

A parliamentary group in the UK House of Commons on 9 June released a report recommending greater collaboration between the Global Fund to Fight AIDS, Tuberculosis and Malaria and other international groups, as well as local governments.

Some international agencies have already begun to pledge funds. In April, the World Bank estimated that up to $\$ 1$ billion dollars could be available to support control programs over the next five years.

On the scientific front, two recent studies show that commercially available biopesticides - fungi that kill bugs - can reduce the number of mosquitoes (Science 308,1638 ; 2005). Researchers in London have isolated a crucial protein that allows the malaria parasite to become resistant to drugs. They ultimately hope to block the cycle of drug resistance. (Nat. Struct. Mol. Biol. doi:10.1038/nsmb947; 2005).

"I think the stars are in alignment," says Brad Herbert, chief of operations for the Global Fund. "This is an opportunity to strike and strike quickly."

Emily Singer, Boston 